\title{
Epidemiologic and Clinical Features of Bell's Palsy among Children in Northern California
}

\author{
Ali Rowhani-Rahbar ${ }^{\mathrm{a}}$ Roger Baxter ${ }^{\mathrm{a}}$ Barry Rasgon ${ }^{\mathrm{b}}$ Paula Ray $^{\mathrm{a}}$ Steven Black $^{\mathrm{c}}$ \\ Jerome O. Klein ${ }^{d}$ Nicola P. Klein ${ }^{a}$ \\ ${ }^{a}$ Kaiser Permanente Vaccine Study Center and ${ }^{b}$ Kaiser Permanente Oakland Medical Center, Oakland, Calif., ${ }^{c}$ Center for \\ Global Health, University of Cincinnati Children's Hospital, Cincinnati, Ohio, and dBoston University School of Medicine, \\ Boston, Mass., USA
}

\section{Key Words}

Bell's palsy $\cdot$ Children $\cdot$ Epidemiology

\begin{abstract}
Background: Bell's palsy (BP) is an acute, idiopathic, and usually unilateral paralysis of the facial nerve. Large populationbased studies of BP among children are lacking. We determined epidemiologic and clinical features of BP among children enrolled in a large integrated health care delivery system. Methods: From 2001 through 2006, all children $\leq 18$ years of age diagnosed with BP within the population of Kaiser Permanente Northern California were identified using the International Classification of Diseases, 9th Revision, code 351.0. All cases were adjudicated by an otolaryngologist and categorized as definite, probable, or rejected. Using chart abstraction forms, epidemiologic and clinical features of BP were determined. Results: Of a total of 977 cases initially identified, 822 (84.1\%) were adjudicated as a definite or probable case. The overall incidence rate of BP during the study period was $18.8(95 \% \mathrm{Cl} 17.6-20.2)$ per 100,000 personyears. The incidence rate increased by age and was higher in females than males across all age strata. There was no evidence for a seasonal pattern in the occurrence of BP ( $p$ for trend $=0.81$ ). Conclusions: $\mathrm{BP}$ among children may be more common than previously recognized.
\end{abstract}

Copyright $\odot 2012$ S. Karger AG, Basel

\section{KARGER}

Fax +4161306 1234

E-Mail karger@karger.ch

www.karger.com (c) 2012 S. Karger AG, Basel

0251-5350/12/0384-0252\$38.00/0

Accessible online at:

www.karger.com/ned

\section{Introduction}

Bell's palsy (BP) is an acute, idiopathic, and usually unilateral paralysis of the seventh cranial nerve. The incidence rate of this disease ranges from 11.5 to 53.3 per 100,000 person-years in different populations [1-5]. BP affects all ages; some studies have suggested that the incidence rate is highest among young and middle-aged adults [6], while others have found a trend of increasing incidence rate with age $[1,2]$. BP is a diagnosis of exclusion. Known congenital (e.g., birth trauma), genetic (e.g., Melkersson-Rosenthal syndrome), and acquired (e.g., certain infections, trauma, benign and malignant tumors) causes of facial nerve paralysis need to be ruled out before the diagnosis of $\mathrm{BP}$ is made [7].

The etiology and pathophysiology of BP are not completely understood; however, infectious (e.g., reactivation of herpes simplex virus type 1 [HSV-1]), immunologic, and vascular factors have been postulated to cause BP [8-12]. Individuals with BP typically present with decreased forehead movement, inability to close the eye, and disappearance of the nasolabial fold on the affected side of the face $[13,14]$. BP is typically a self-limiting disorder with a favorable prognosis; however, its abrupt onset, rapid progression, and dramatic presentation can be frightening, especially when it occurs in a child.

Ali Rowhani-Rahbar, MD, MPH, PhD

Kaiser Permanente Vaccine Study Center

One Kaiser Plaza, 16th Floor

Oakland, CA 94612

Tel. +1 510267 7502, E-Mail ali.x.rowhani-rahbar@kp.org 
Table 1. Criteria for adjudication of a case of BP

Definite

All the criteria listed below had to be met:

(1) There was a definitive diagnosis of BP in the chart

AND

(2) Unilateral weakness of all facial muscles including forehead, eyelid, mouth, and cheek muscles was explicitly specified in the chart

AND

(3) The disease onset was acute with maximum paresis within $72 \mathrm{~h}$ following initial signs

AND

(4) There was no:

History of head trauma within 30 days prior to the diagnosis

History of ipsilateral otologic disease within 30

days prior to the diagnosis

History of cerebrovascular incident

History of otologic surgery

History of brain tumor

Diagnosis of sickle cell disease

Diagnosis of Guillain-Barré syndrome

Evidence of other neurologic signs such as

weakness of an extremity, coordination

abnormalities, other reflex or strength

abnormalities, or asymmetries

Probable

Probable cases were children with facial weakness who met the criteria above except in whom the involvement of all facial muscles was not documented or the period of time between initial signs and maximum paresis was not documented or more than $72 \mathrm{~h}$

Rejected

Rejected cases were children who did not meet the case definition due to absence of any facial muscle weakness or the presence of another cause for facial muscle weakness

Knowledge of epidemiology and clinical features of BP largely stems from studies of this disease among adults. Substantially less is known about epidemiologic and clinical features of BP among children. In this report, we provide results of a population-based study of $\mathrm{BP}$ among children $\leq 18$ years of age enrolled in a large integrated health care delivery system in Northern California, USA. Our specific aims were to determine the incidence rate of $\mathrm{BP}$, describe demographic characteristics of cases, and assess clinical features of the disease in this population.

\section{Materials and Methods}

This study was conducted within the population of Kaiser Permanente Northern California (KPNC) and was approved by the KPNC Institutional Review Board. KPNC is a large integrated health care delivery system with approximately 3.2 million members. The population covered by KPNC is heterogeneous with regard to age, sex, race, and socioeconomic status and represents the region's underlying census distribution, except at extremes of income $[15,16]$. Therefore, investigations carried out within this population accurately approximate population-based studies. KPNC maintains a large administrative database that captures all outpatient, emergency department, and inpatient encounters within the system. Encounters authorized by KPNC providers for health plan members supplied in non-KPNC facilities as well as claims for reimbursement by health plan members that were not authorized by KPNC providers are also captured in databases.

From January 1, 2001, through December 31, 2006, all children $\leq 18$ years of age diagnosed with BP were identified using the International Classification of Diseases, 9th Revision (ICD-9), code 351.0. Cases were included in the analysis if they were members of KPNC when diagnosed with BP. Retrospective chart reviews were conducted to extract information on demographic characteristics, history of present illness, past medical history, family history, diagnostic tests, and treatment options used for these children. Individuals identified during chart review as having had a history of BP prior to the start of the study period were excluded from the analyses. An otolaryngologist reviewed all cases using a case disposition form and categorized each as definite, probable, or rejected. The case definition for this study was developed based on a literature review and consensus among the authors (table 1).

The annual incidence rate of BP in each year from 2001 through 2006 and age- and sex-specific incidence rates of BP during the study period were calculated using the corresponding mid-year population of KPNC as the denominator. Exact 95\% confidence intervals (CI) for incidence rates were calculated using the Poisson distribution. Incidence rates were separately calculated for definite cases only and definite and probable cases combined. The Cochran-Armitage test of trend was used to evaluate seasonality and secular trend in the occurrence of BP. Season was categorized into three mutually exclusive strata of 'warm' (May through September), 'transitional' (April and October), and 'cold' (November through March) to be consistent with the previous literature [17]. All statistical analyses were conducted using Stata 11 (StataCorp, College Station, Tex., USA).

\section{Results}

During the study period, 977 children $\leq 18$ years of age were identified with an ICD-9 code for BP as indicated in their electronic records. Following chart review and adjudication, 119 children were rejected as cases. An additional 36 children were excluded from the analysis due to a previous history of BP. Of the remaining 822 children, $208(25.3 \%)$ and $614(74.7 \%)$ were categorized as 


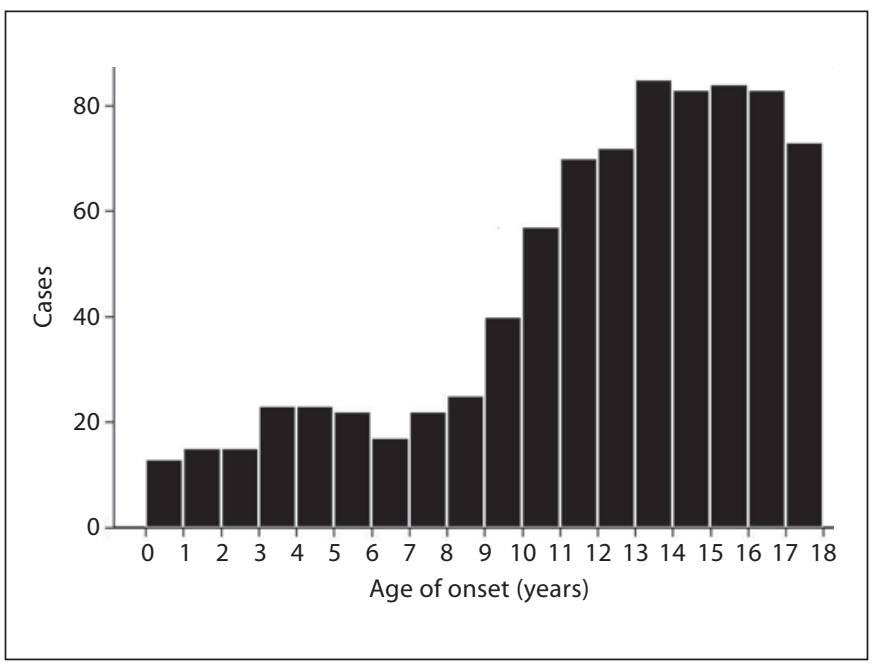

Fig. 1. Age histogram of BP cases.

definite and probable cases, respectively. The reasons for being classified as a probable were that involvement of all facial muscles was not noted $(\mathrm{n}=445)$ and/or maximum paresis did not occur within $72 \mathrm{~h}$ following the onset of the initial signs $(\mathrm{n}=355)$.

Demographic characteristics of the study population are shown in table 2 . The majority of cases were $\geq 10$ years of age (fig. 1). Three cases were pregnant at the time of onset of signs and symptoms. Among cases for whom data regarding family history of BP was available $(\mathrm{n}=$ 543), 46 (8.5\%) indicated that at least one member of their family had previously been diagnosed with BP. The overall incidence rate of BP for definite cases only, and definite and probable cases combined, was 4.8 (95\% CI 4.15.5) and 18.8 (95\% CI 17.6-20.2) per 100,000 personyears, respectively. From 2001 through 2006, the annual incidence rate of $\mathrm{BP}$ in the study population did not change significantly (table 3 ; $\mathrm{p}$ for trend $=0.68$ ). The incidence rate increased by age; in particular, it was noticeably higher among children $\geq 10$ years of age. Regardless of age, the incidence rate was consistently higher among females than males (table 4). There was no evidence of a seasonal pattern in the occurrence of BP in this population (fig. 2; $\mathrm{p}$ for trend $=0.81$ ).

Clinical features of cases are presented in table 5. A total of $93(11.3 \%)$ cases were tested for blink response, 86 $(92.5 \%)$ of whom tested abnormal, indicating their inability to blink due to the facial nerve palsy on the affected side of the face. Head computed tomography (CT) and magnetic resonance imaging (MRI) scans were conduct-
Table 2. Demographic characteristics of the study population

\begin{tabular}{|c|c|c|}
\hline Characteristic & $\begin{array}{l}\text { Definite cases } \\
(\mathrm{n}=208)\end{array}$ & $\begin{array}{l}\text { All }^{\mathrm{a}} \text { cases } \\
(\mathrm{n}=822)\end{array}$ \\
\hline \multicolumn{3}{|l|}{ Age, years } \\
\hline Mean & 11.9 & 12.0 \\
\hline Range & 126 days - 17.9 years & 10 days -17.9 years \\
\hline \multicolumn{3}{|l|}{ Sex, n (\%) } \\
\hline Female & $120(57.7)$ & $487(59.3)$ \\
\hline Male & $88(42.3)$ & $335(40.7)$ \\
\hline \multicolumn{3}{|l|}{ Race $^{\mathrm{b}}, \mathrm{n}(\%)$} \\
\hline White & $82(55.4)$ & $359(61.0)$ \\
\hline Black & $26(17.6)$ & $98(16.7)$ \\
\hline Asian & $23(15.5)$ & $97(16.5)$ \\
\hline Other & $17(11.5)$ & $34(5.8)$ \\
\hline \multicolumn{3}{|l|}{ Ethnicity ${ }^{\mathrm{c}}, \mathrm{n}(\%)$} \\
\hline Hispanic & $89(53.9)$ & $336(50.2)$ \\
\hline Non-Hispanic & $76(46.1)$ & $333(49.8)$ \\
\hline $\begin{array}{l}{ }^{a} \text { Includes defin } \\
{ }^{b} \text { Race was not } \\
{ }^{c} \text { Ethnicity was }\end{array}$ & $\begin{array}{l}\text { e and probable cases. } \\
\text { lown for } 234 \text { cases. } \\
\text { ot known for } 153 \text { case }\end{array}$ & \\
\hline
\end{tabular}

Table 3. Incidence rate of BP in the study population by year

\begin{tabular}{lrllll}
\hline Year & \multicolumn{2}{l}{ Definite cases } & & \multicolumn{2}{l}{ All $^{\mathrm{a}}$ cases } \\
\cline { 2 - 3 } \cline { 5 - 6 } & $\mathrm{n}$ & $\begin{array}{c}\text { incidence rate } \\
(95 \% \mathrm{CI})\end{array}$ & & $\mathrm{n}$ & $\begin{array}{l}\text { incidence rate } \\
(95 \% \mathrm{CI})\end{array}$ \\
\hline 2001 & 41 & $5.6(4.0-7.6)$ & & 143 & $19.6(16.5-23.1)$ \\
2002 & 28 & $3.8(2.5-5.5)$ & & 129 & $17.6(14.7-20.9)$ \\
2003 & 24 & $3.3(2.1-4.9)$ & & 142 & $19.5(16.4-23.0)$ \\
2004 & 40 & $5.6(4.0-7.7)$ & & 146 & $20.5(17.4-24.2)$ \\
2005 & 43 & $5.9(4.3-8.0)$ & & 134 & $18.4(15.4-21.8)$ \\
2006 & 32 & $4.3(3.0-6.1)$ & & 128 & $17.3(14.5-20.6)$ \\
Total & 208 & $4.8(4.1-5.5)$ & & 822 & $18.8(17.6-20.2)$ \\
\hline
\end{tabular}

${ }^{\text {a }}$ Includes definite and probable cases.

b Per 100,000 person-years.

ed among 64 and 39 cases and reported as abnormal in 9 and 11 cases, respectively. These findings were incidental and of no etiologic significance. A total of 27 (3.3\%) cases were diagnosed with recurrent BP. Of a total of 735 cases who received some treatment, 638 (86.8\%), 490 (66.7\%), 323 (43.9\%), and 75 (10.2\%) received a corticosteroid, antiviral, eye lubricant, and an antibacterial medication, respectively. A total of 453 cases (61.6\%) received both prednisone and acyclovir. The overwhelming majority of pa- 
Table 4. Age- and sex-specific incidence rates of BP in the study population

\begin{tabular}{|c|c|c|c|c|c|c|c|c|}
\hline \multirow[t]{3}{*}{ Age group } & \multicolumn{4}{|c|}{ Female } & \multicolumn{4}{|c|}{ Male } \\
\hline & \multicolumn{2}{|c|}{ definite cases } & \multicolumn{2}{|c|}{ all $^{\mathrm{a}}$ cases } & \multicolumn{2}{|c|}{ definite cases } & \multicolumn{2}{|c|}{ all $^{\mathrm{a}}$ cases } \\
\hline & $\mathrm{n}$ & $\begin{array}{l}\text { incidence rate } \\
(95 \% \text { CI })\end{array}$ & $\mathrm{n}$ & $\begin{array}{l}\text { incidence rate } \\
(95 \% \text { CI })\end{array}$ & $\mathrm{n}$ & $\begin{array}{l}\text { incidence rate } \\
(95 \% \text { CI })\end{array}$ & $\mathrm{n}$ & $\begin{array}{l}\text { incidence rate } \\
(95 \% \text { CI })\end{array}$ \\
\hline $0-4$ years & 11 & $2.1(1.1-3.9)$ & 55 & $10.8(8.1-14.0)$ & 7 & $1.3(0.5-2.7)$ & 34 & $6.4(4.4-8.9)$ \\
\hline $5-9$ years & 24 & $4.1(2.7-6.2)$ & 78 & $13.5(10.7-16.8)$ & 16 & $2.7(1.5-4.3)$ & 48 & $8.0(5.9-10.6)$ \\
\hline $10-14$ years & 50 & $7.7(5.7-10.1)$ & 213 & $32.7(28.5-37.4)$ & 47 & $6.9(5.1-9.2)$ & 155 & $22.8(19.4-26.7)$ \\
\hline $15-18$ years & 35 & $8.8(6.1-12.2)$ & 141 & $35.5(29.9-41.8)$ & 18 & $4.4(2.6-6.9)$ & 98 & $23.7(19.3-28.9)$ \\
\hline Total & 120 & $5.6(4.6-6.7)$ & 487 & $22.8(20.8-24.9)$ & 88 & $3.9(3.2-4.9)$ & 335 & $15.0(13.5-16.7)$ \\
\hline
\end{tabular}

${ }^{a}$ Includes definite and probable cases. ${ }^{\mathrm{b}}$ Per 100,000 person-years.

tients $(805 / 822=97.9 \%)$ recovered with a median time of 8 days from onset to last visit when signs and symptoms were still present.

\section{Discussion}

To our knowledge, this study represents the largest population-based investigation of BP among children. Our estimated incidence rates of BP using definite cases only are consistent with those obtained in previous studies conducted in the USA $[1,2,12,18]$. Those studies reported incidence rates of up to 4.6 and 7.1 per 100,000 person-years among males and females $0-9$ years of age, and incidence rates of up to 10.5 and 20.3 per 100,000 person-years among males and females 10-19 years of age, respectively. However, our estimated incidence rates of BP using definite and probable cases combined are higher than those reported previously in children.

This difference could stem from several factors. First, the study setting and population as well as methods of case definition and ascertainment used in those studies were different than ours. For instance, Brandenburg and Annegers [1] discuss that their reliance upon referral diagnosis of BP for most cases ascertained in Laredo, Tex., may have led to an underestimation of incidence rates in their study. In addition, the degree of certainty in the diagnosis of BP is not fully known or characterized in previous studies; thus, it is conceivable that a portion of true cases of BP were not included in the analysis leading to an underestimation of the incidence rate. Second, previous studies included a substantially smaller number of children with BP than our study. For instance, studies conducted in Laredo, Tex. [1], and Rochester, Minn. [2],

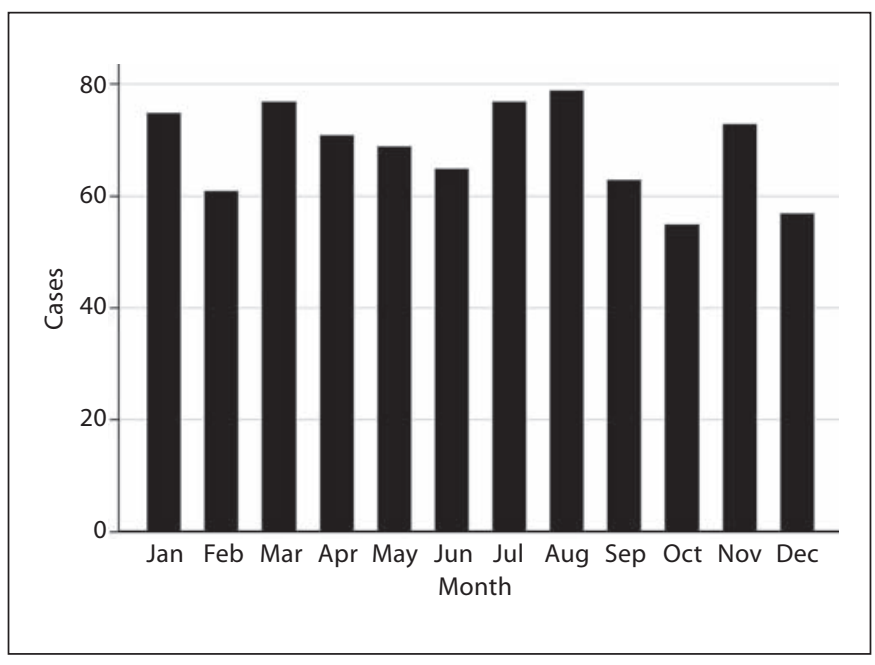

Fig. 2. Distribution of BP cases by month of onset.

included only 28 and 36 children with BP, respectively. Therefore, our estimates of the incidence rate of $\mathrm{BP}$ are more precise. Finally, it is conceivable that a portion of probable cases in our study population were not true cases of BP, which in turn resulted in an overestimation of the incidence rate when definite and probable cases were combined. However, since our definition for a definite case of BP was strict, it is likely that the incidence rate of $\mathrm{BP}$ among children may in fact be higher than what has been previously reported in the literature.

Consistent with the results of few studies that have reported the incidence rate of $\mathrm{BP}$ among children, we found an increasing trend by age $[1,2,4]$. Our results further suggest that the incidence rate of $\mathrm{BP}$ in the second decade 
Table 5. Clinical characteristics of the study population

\begin{tabular}{|c|c|c|}
\hline Clinical feature & $\begin{array}{l}\text { Definite cases } \\
(\mathrm{n}=208)\end{array}$ & $\begin{array}{l}\text { All }^{\mathrm{a}} \text { cases } \\
(\mathrm{n}=822)\end{array}$ \\
\hline \multicolumn{3}{|c|}{ Specialty of the physician who initially diagnosed the case $\mathrm{e}^{\mathrm{b}}, \mathrm{n}(\%)$} \\
\hline Pediatrician & $183(88.0)$ & $729(88.7)$ \\
\hline Emergency medicine specialist & $36(17.3)$ & $112(13.6)$ \\
\hline Internist & $2(1.0)$ & $28(3.4)$ \\
\hline Otolaryngologist & $10(4.8)$ & $28(3.4)$ \\
\hline Neurologist & $20(9.6)$ & $47(5.7)$ \\
\hline Other & $8(3.8)$ & $32(3.9)$ \\
\hline Median time from onset to diagnosis, days & 2 & 2 \\
\hline Median time from onset to maximum paresis, days & 1 & 2 \\
\hline \multicolumn{3}{|c|}{ Median time from onset to last visit when signs and symptoms } \\
\hline were still present, days & 9 & 8 \\
\hline \multicolumn{3}{|l|}{ Laterality of the facial muscle involvement, $\mathrm{n}(\%)$} \\
\hline Unilateral & $208(100)$ & $807(98.2)$ \\
\hline Bilateral & 0 & $15(1.8)$ \\
\hline \multicolumn{3}{|l|}{ Involved side of the face ${ }^{c}, \mathrm{n}(\%)$} \\
\hline Right & $114(54.8)$ & $426(53.1)$ \\
\hline Left & $94(45.2)$ & $376(46.9)$ \\
\hline \multicolumn{3}{|l|}{ Type of involved muscle, n (\%) } \\
\hline Forehead & $208(100)$ & $378(47.1)$ \\
\hline Eyelid & $208(100)$ & $735(91.6)$ \\
\hline Cheek & $208(100)$ & $669(83.4)$ \\
\hline Mouth & $208(100)$ & $763(95.1)$ \\
\hline \multicolumn{3}{|l|}{ History of illness within 90 days prior to diagnosis, $\mathrm{n}(\%)$} \\
\hline Any respiratory illness & $58(27.9)$ & $189(23.0)$ \\
\hline Herpes simplex virus infection & $14(6.7)$ & $39(4.7)$ \\
\hline Varicella zoster virus infection & $4(1.9)$ & $9(1.1)$ \\
\hline \multicolumn{3}{|l|}{ Lifetime history of illness ${ }^{\mathrm{d}}, \mathrm{n}(\%)$} \\
\hline Head trauma & $34(16.3)$ & $121(14.7)$ \\
\hline Central nervous system disease (e.g., epilepsy) & $8(3.8)$ & $30(3.6)$ \\
\hline Hypertension & $4(1.9)$ & $9(1.1)$ \\
\hline Diabetes & 0 & $4(0.5)$ \\
\hline \multicolumn{3}{|c|}{$\begin{array}{l}{ }^{a} \text { Includes definite and probable cases. }{ }^{b} \text { Numbers add to more than total and percentages add to more than } \\
100 \% \text { due to overlap between the categories. }{ }^{c} \text { The involved side of the face was unknown for } 5 \text { cases. }{ }^{d} \text { No cas } \\
\text { reported a history of human immunodeficiency virus infection, Lyme disease, or a parotid tumor. }{ }^{\mathrm{e}} \text { The his } \\
\text { tory of head trauma does not include the period of time within } 30 \text { days prior to diagnosis. A history of heac } \\
\text { trauma within } 30 \text { days prior to diagnosis was an exclusion criterion in the case definition as described in the } \\
\text { Materials and Methods section. }\end{array}$} \\
\hline
\end{tabular}

of life is considerably higher than that in the first decade of life. The reason for such a trend is not clear. One hypothesis is the increased cumulative exposure to microbial agents by time. Specifically, several studies have indicated HSV-1 as a potential infectious etiology for BP [8-10]. Increased likelihood of exposure to this virus may partially explain the observed difference in the incidence rate of BP between the first and second decade of life. Other environmental and physiologic factors may also play a role; future research in this area is warranted.
Interestingly, we found a higher incidence rate of $\mathrm{BP}$ among females than males in our study population. A few studies with considerably smaller sample size of children have also reported a female-to-male ratio of $>1[1,2,12$, 19, 20]. For instance, Adour et al. [12] found that among individuals 10-19 years of age, BP was twice as common in females and postulated that this observation may have pertained to menarche. In addition, pregnancy appears to be a risk factor for BP potentially due to physical or hormonal changes [21]. In our study, the incidence rate of 
BP was higher among females than males across all age strata, even among young children, and only 3 cases were pregnant at the time of diagnosis. Future studies should assess whether the observed gender difference in this study could be potentially described by differences in the incidence rate of autoimmune disorders, infectious diseases, or other factors.

The occurrence of BP among children in this study did not show a clear seasonal pattern. Findings of previous studies with regard to the seasonality of BP are inconsistent. Some studies have suggested that the cold season is associated with a higher occurrence of $\mathrm{BP}[5,17,22,23]$, while others have not observed any seasonal variations [1, $12,24]$. None of those earlier studies evaluated the seasonality of BP in as large a study as the one used here. Future studies should assess whether an interaction exists between age, season, and geographic location in the development of BP.

Our study is subject to some limitations. First, a relatively large portion of cases were categorized as probable. As mentioned, our pre-specified definition of a definite case was strict. The documentation of the involvement of all facial muscles in a child could be quite challenging. It was not clear whether the diagnosing physician had tested a full battery of movements (e.g., moving forehead, raising eyebrows, and smiling), and even if they had, subtle changes could have been missed or not recorded. Therefore, it is conceivable that the majority of cases categorized as probable in this study were clinically definitive cases of BP. Second, race and ethnicity were unknown for some cases. Despite this limitation, we found that among cases whose ethnicity was known one half were Hispanic. Approximately $30 \%$ of children $\leq 18$ years of age in the KPNC population are Hispanic; therefore, the distribution of ethnicity among cases in this study suggests an over-representation of Hispanics. It has been suggested that Hispanics may be more vulnerable to BP for unknown reasons [2]; this hypothesis requires further investigation. Third, due to the nature of the study, we did not follow up cases to fully determine the recovery status and the date of recovery. However, we did extract and present information on the date of last visit when signs and symptoms of BP were still present, and using information on the date of first visit when signs and symptoms were absent, determined the number of recovered cases. Finally, while we used a pre-specified case disposition form for adjudication of the cases, there is a need for a standard case definition of BP to facilitate comparisons across different studies. The Brighton Collaboration has formed an international working group to define BP as an adverse event following immunization [25]. Such a case definition could be of use in future epidemiologic studies of BP.

\section{Conclusion}

The results of this study suggest that $\mathrm{BP}$ among children may be more common than previously recognized. Large studies to investigate the epidemiology and clinical features of BP among children in other settings are needed. In particular, future studies should determine the incidence rate of $\mathrm{BP}$ using a standard case definition and evaluate the role of gender, race, and ethnicity in the occurrence of this disease among children.

\section{Acknowledgments}

The authors wish to thank Pat Ross, Ajit DeSilva, and Joan Bartlett from the KPNC Vaccine Study Center for their contribution to this project. This study was funded by the Vaccine Safety Datalink and Clinical Immunization Safety Assessment Network through a subcontract with America's Health Insurance Plans Vaccine Safety Fellowship Program under contract 200-200200732 from the United States Centers for Disease Control and Prevention. The findings and conclusions in this report are those of the authors and do not necessarily represent the official position or views of the United States Centers for Disease Control and Prevention.

\section{Disclosure Statement}

The authors report no conflicts of interest.

\section{References}

1 Brandenburg NA, Annegers JF: Incidence and risk factors for Bell's palsy in Laredo, Texas: 1974-1982. Neuroepidemiology 1993; 12:313-325.

2 Katusic SK, Beard CM, Wiederholt WC, Bergstralh EJ, Kurland LT: Incidence, clinical features, and prognosis in Bell's palsy,
Rochester, Minnesota, 1968-1982. Ann Neurol 1986;20:622-627.

-3 Monini S, Lazzarino AI, Iacolucci C, Buffoni A, Barbara M: Epidemiology of Bell's palsy in an Italian health district: incidence and case-control study. Acta Otorhinolaryngol Ital 2010;30:198. 
4 Rowlands S, Hooper R, Hughes R, Burney P: The epidemiology and treatment of Bell's palsy in the UK. Eur J Neurol 2002;9:63-67.

$>5$ Tsai HS, Chang LY, Lu CY, Lee PI, Chen JM, Lee CY, Huang LM: Epidemiology and treatment of Bell's palsy in children in Northern Taiwan. J Microbiol Immunol Infect 2009; 42:351-356.

6 Peitersen E: Bell's palsy: the spontaneous course of 2,500 peripheral facial nerve palsies of different etiologies. Acta Otolaryngol Suppl 2002:4-30

7 Lorch M, Teach SJ: Facial nerve palsy: etiology and approach to diagnosis and treatment. Pediatr Emerg Care 2010;26:763-769; quiz 770-763.

$>8$ Abiko Y, Ikeda M, Hondo R: Secretion and dynamics of herpes simplex virus in tears and saliva of patients with Bell's palsy. Otol Neurotol 2002;23:779-783.

9 Lazarini PR, Vianna MF, Alcantara MP, Scalia RA, Caiaffa Filho HH: Herpes simplex virus in the saliva of peripheral Bell's palsy patients. Braz J Otorhinolaryngol 2006;72: 7-11.

10 Murakami S, Mizobuchi M, Nakashiro Y, Doi T, Hato N, Yanagihara N: Bell palsy and herpes simplex virus: identification of viral DNA in endoneurial fluid and muscle. Ann Intern Med 1996;124:27-30.
11 Paolino E, Granieri E, Tola MR, Panarelli MA, Carreras M: Predisposing factors in Bell's palsy: a case-control study. J Neurol 1985;232:363-365.

12 Adour KK, Byl FM, Hilsinger RL Jr, Kahn ZM, Sheldon MI: The true nature of Bell's palsy: analysis of 1,000 consecutive patients. Laryngoscope 1978;88:787-801.

13 Wilson-Pauwels L, Akesson EJ, Stewart PA: Cranial Nerves: Anatomy and Clinical Comments. Philadelphia, B.C. Decker, 1988.

14 Shargorodsky J, Lin HW, Gopen Q: Facial nerve palsy in the pediatric population. Clin Pediatr (Phila) 2010;49:411-417.

15 Krieger N: Overcoming the absence of socioeconomic data in medical records: validation and application of a census-based methodology. Am J Public Health 1992;82:703-710.

16 Strom BL: Pharmacoepidemiology, ed 4. New York, Wiley, 2005.

17 Campbell KE, Brundage JF: Effects of climate, latitude, and season on the incidence of Bell's palsy in the US armed forces, October 1997 to September 1999. Am J Epidemiol 2002; 156:32-39.

18 Hauser WA, Karnes WE, Annis J, Kurland LT: Incidence and prognosis of Bell's palsy in the population of Rochester, Minnesota. Mayo Clin Proc 1971;46:258-264.

19 Lockhart P, Daly F, Pitkethly M, Comerford N, Sullivan F: Antiviral treatment for Bell's palsy (idiopathic facial paralysis). Cochrane Database Syst Rev 2009:CD001869.
20 Quant EC, Jeste SS, Muni RH, Cape AV, Bhussar MK, Peleg AY: The benefits of steroids versus steroids plus antivirals for treatment of Bell's palsy: a meta-analysis. BMJ 2009;339:b3354.

21 Hilsinger RL Jr, Adour KK, Doty HE: Idiopathic facial paralysis, pregnancy, and the menstrual cycle. Ann Otol Rhinol Laryngol 1975;84:433-442.

22 Unuvar E, Oguz F, Sidal M, Kilic A: Corticosteroid treatment of childhood Bell's palsy. Pediatr Neurol 1999;21:814-816.

23 Spengos K, Sameli S, Stouraitis G, Kolias A, Koulouri O, Kokkinos Z, Makrylou I, Tsivgoulis A, Tsivgoulis G, Vassilopoulos D: Seasonal variation of Bell's palsy in Athens, Greece - a hospital-based retrospective evaluation over fifteen years. Eur Neurol 2006; 55:84-88.

24 de Almeida JR, Al Khabori M, Guyatt GH, Witterick IJ, Lin VY, Nedzelski JM, Chen JM: Combined corticosteroid and antiviral treatment for Bell palsy: a systematic review and meta-analysis. JAMA 2009;302:985-993.

25 Rath B, Linder T, Cornblath D, Hudson M, Fernandopulle R, Hartmann K, Heininger U, Izurieta H, Killion L, Kokotis P, Oleske J, Vajdy M, Wong V: All that palsies is not Bell's - the need to define Bell's palsy as an adverse event following immunization. Vaccine 2007;26:1-14. 